\title{
Doctors without borders in British Columbia
}

$\mathrm{I}$ t was Christmas Day, 2008. My wife, Mary Nishi-Lince, and I were standing in line to pay for our dinner of microwaved samosas, taquitos and soup at the 7-11 store beside the local gas station.

It was evening in Northern British Columbia and as far as we knew, all the restaurants were closed for dinner on that snow-covered night.

I have been a general surgeon in Canada for nearly 40 years and normally work out of Richmond, Delta and UBC Hospitals in Metro Vancouver.

We were waiting in the long line-up at the 7-11 to pay for our Christmas dinner.

What were we doing there on that cold night?

We like to joke and call it "Doctors Without Borders in BC."

I used to be a semi-retired general surgeon, enjoying the mild climate of the West Coast. But in 2008, I decided to work for the Rural Specialist Locum Program of British Columbia.

Do I find working in rural areas a lonely experience?

The life of a locum physician can be quite busy, yet lonely and often boring. But my wife often accompanied me, which helped ease the sense of isolation. She kept busy doing paperwork associated with my practice, taking pictures of the local environment, or creating DVD videos of towns where I was practising. We were away from home from one to three weeks at a time.

We kept in touch with friends and family by email and spent many an hour reading medical and economic news on our laptop. Sometimes we brought Pancho, our travelling cat on a trip. So, in essence, our home life travelled with us.

How much paperwork is involved?

My wife is my secretary and she has learned to deal with the abundance of paperwork that seems part of modern

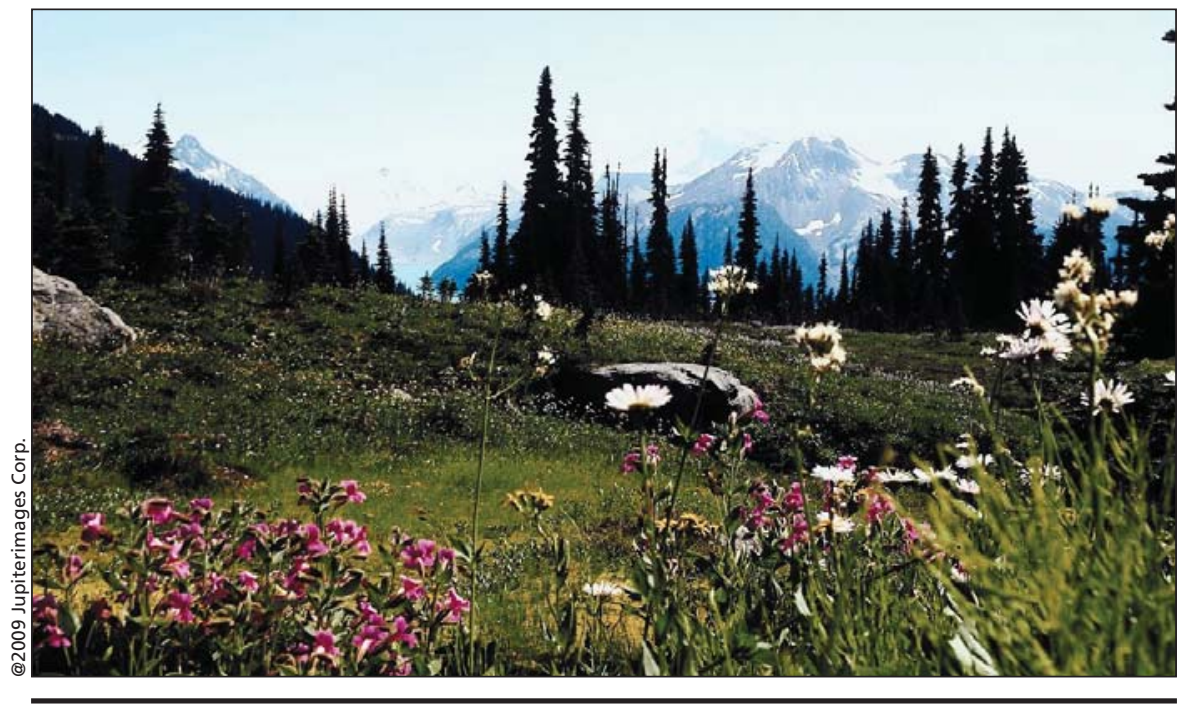

Northern British Columbia offers beautiful scenery, but life for a locum physician in remote parts of the province can be lonely and boring.

practice. She has dealt with a number of health authorities in BC: Northern Health, Vancouver Island Health, Vancouver Coastal Health, and Interior Health. Each has its own borders, rules and governing boards.

Is it a tough life for a specialist or physician to do locums?

The short answer is "yes." In some areas, there is a lack of radiology services after hours, weekends and holidays. Each locum position is a learning experience: there is another maze of hospital corridors to remember, new names of colleagues, different tools and equipment in the operating room, and new streets to remember, which can be challenging during rushed drives to the emergency room on snow-covered or poorly lit streets.

It takes a lot of planning and coordination to do the paperwork and make the necessary travel arrangements. Many times, locum positions are offered on short notice.

A surgeon may be responsible for a catch-basin of 15000 people, or even more, in a rural area. Patient transporta- tion and referral can be challenging due to weather conditions or lack of cooperation from major hospital centres.

Besides a reasonable income, what are the additional benefits for physicians to do locums?

We saw a great deal of our province. "Beautiful BC" is more than just nature. We visited a lot of local shops, and ate at some altogether memorable restaurants and the odd forgettable eatery. We met a lot of nice, hardworking people including patients, doctors, nurses and hospital personnel. Dr. Dario Lince, Richmond, BC

\section{DOI:10.1503/cmaj.109-3009}

CMAJ invites contributions to "Dispatches from the medical front," in which physicians and other health care providers offer eyewitness glimpses of medical frontiers, whether defined by location or intervention. Submissions, which must run a maximum 700 words, should be forwarded to: wayne.kondro @ cmaj.ca 